\title{
CORRIGENDUM
}

\section{Bax deficiency prolongs cerebellar neurogenesis, accelerates medulloblastoma formation and paradoxically increases both malignancy and differentiation}

I Garcia, AJ Crowther, V Gama, CR Miller, M Deshmukh and TR Gershon

Oncogene (2015) 34, 3881; doi:10.1038/onc.2015.204

Correction to: Oncogene (2013) 32, 2304-2314; doi:10.1038/onc. 2012.248; published online 18 June 2012
Since the publication of the above paper, the author listed as $C$ Ryan Miller has requested that the listing of his name be changed to CR Miller. 